\title{
The Association of Serum Total Cholesterol, Triglycerides Level and The Presence of Diabetic Neuropathy
}

\section{Eriska Retno Indarti ${ }^{1}$, Santoso Jaeri ${ }^{2,3 *}$, Amallia Nuggetsiana Setyawati $^{2}$ and Indranila Kustarini Samsuria ${ }^{4}$}

${ }^{1}$ Deparetment of Medicine, Faculty of Medicine, Diponegoro University, Semarang Indonesia

${ }^{2}$ Department of Medical Biology and Biochemistry, Faculty of Medicine, Diponegoro University, Semarang, Indonesia

${ }^{3}$ Department of Neurology, National Hospital Diponegoro, Diponegoro University, Semarang Indonesia

${ }^{4}$ Department of Clinical Pathology, Faculty of Medicine, Diponegoro University, Semarang Indonesia

*Corresponding Author: Santoso Jaeri, Department of Medical Biology and Biochemistry, Faculty of Medicine, Diponegoro University, Semarang, Indonesia.
Received: March 05, 2021

Published: April 26, 2021

(C) All rights are reserved by Santoso Jaeri., et al.

\footnotetext{
Abstract

Background: Diabetic neuropathy (DN) is the most common complication of diabetes mellitus resulting in a decrease in quality of life. The association between lipid profiles and the presence of DN is controversial. We investigated the association of total cholesterol, triglycerides levels, and the presence of diabetic neuropathy.

Methodology: A cross-sectional study among seventy diabetic types 2 patients with $(n=35)$ and without diabetic neuropathy $(n=$ 35). The presence of diabetic neuropathy was evaluated using the Michigan Neuropathy Screening Instrument (MNSI) and asked for fasting venous blood collection for the examination of total cholesterol using the CHOD-PAP method and triglycerides using GPO-PAP method. The association of serum total cholesterol and triglyceride level and the presence of DN were obtained from Chi-square test analysis.

Results: The serum total cholesterol level in diabetic type 2 patients with DN is $211.11 \pm 39,29 \mathrm{mg} / \mathrm{dL}$, while in diabetic type 2 patients without DN is $190,45 \pm 60.24 \mathrm{mg} / \mathrm{dL}$. The serum triglycerides level in diabetic type 2 patients with DN is $148.57 \pm 42.19 \mathrm{mg} /$ $\mathrm{dL}$ while in diabetic type 2 patients without $\mathrm{DN}$ is $132,78 \pm 42,18 \mathrm{mg} / \mathrm{dL}$. We found there is association between the serum total cholesterol levels and the presence of $\mathrm{DN},(\mathrm{p}=0.017$, odd ratio (OR) $=3.244,95 \%$ confidence interval $(95 \% \mathrm{CI})=1.219-8.629)$ but no for the serum triglyceride levels ( $\mathrm{p}=0.051, \mathrm{OR}=2.647,95 \% \mathrm{CI}=0.985-7.113)$.

Conclusion: There was a significant association between the serum total cholesterol levels and the presence of DN, but no for the serum triglycerides levels.
}

Keywords: Diabetic Neuropathy; Total Cholesterol; Triglycerides; Michigan Neuropathy Screening Instrument

\section{Abbreviations}

DN: Diabetic Neuropathy; MNSI: Michigan Neuropathy Screening Instrument; CHOD-PAP: Aminoantipyrine Phenol Cholesterol Oxidase-Peroxidase; GPO-PAP: Glycerol-3-phosphate oxidase-Peroxi- dase; OR: Odd Ratio; BMI: Body Mass Index; CI: Confidence Interval; STROBE: Strengthening the Reporting of Observational Studies in Epidemiology; Kg: Kilograms; Cm: Centimeter; M: Meter; mg/dL: Milligrams/Deciliters; DAG: Diacylglycerol 


\section{Introduction}

Diabetic neuropathy (DN) is the most common complication in diabetic patients [1]. DN is defined as abnormal nerve function resulted from complex mechanisms on the peripheral nervous system caused by chronic hyperglycemia among diabetic patients [2]. There are several signs and symptoms of DN including loss of sensation or numbness, impaired pressure distribution in the feet, decreased sweat, and bladder and erectile dysfunction [8]. DN affect the quality of life and also increases the cost of care fourfold from the cost of treating Type 2 diabetic patients $[1,4]$.

There are several risk factors affecting the prevalence of DN such as the duration of diabetes, gender, and age. The occurrence of DN is more common in women and the elderly. Another risk factors of DN are the regularity of diabetes medication, diet, physical activity, and history of hypertension [4-6].

There are controversial shreds of evidence regarding the effect of total cholesterol and triglyceride levels on the presence of DN. Some studies demonstrated that the increased total cholesterol and triglyceride levels play a significant role in DN by inducing oxidative stress in sensory ganglia which can cause nerve damage [7]. Other studies also revealed that the increase of total cholesterol levels is correlated with loss of myelin fiber density, a marker of the progression of DN [8]. A study conducted in Brazil reported that there was a significant correlation between total cholesterol levels and peripheral DN scores [9]. But Another study conducted in Iraq reported that total cholesterol levels were not related to the incidence of peripheral and autonomic DN [10].

We conducted this study to determine the association of serum total cholesterol and triglyceride levels with the presence of DN to gain our knowledge regarding the role of the total cholesterol and triglyceride on the pathogenesis of DN in order to develop the intervention strategies in the DN management.

\section{Research Methodology and Design}

This study was an observational cross-sectional study among type 2 diabetes patients who visited the Neurology and the Internal Medicine outpatient clinics of Diponegoro National Hospital Semarang Indonesia period July-August 2019.

The subjects were obtained by consecutive admission sampling method, with inclusion criteria: 18 years of age or more, and willing to take the study, and exclusion criteria: has another complication of type 2 diabetes such as nephropathy, and stroke assessed from the interview and confirmed from the medical record. A total of seventy ( 35 with DN and 35 without DN) participant recruited from the formula of sample size for the testing hypothesis of two proportion.

The diagnosis of DN was obtained by screening neuropathy using the Michigan Neuropathy Screening Instrument (MNSI), then the demographic and clinical characteristics including gender, body mass index (BMI) category, age, weight, height of the body, and fasting blood glucose levels were recorded. The subject then was asked for fasting at least 8 hours for venous blood collection for the examination of the serum total cholesterol and triglyceride levels. In order to report, this study apply the Strengthening the Reporting of Observational Studies in Epidemiology STROBE cross-sectional reporting guideline [11].

Examination of serum total cholesterol and triglyceride levels

The level of serum total cholesterol triglyceride was examined in the Department of Clinical Pathology Diponegoro National Hospital Semarang Indonesia. The serum total cholesterol levels were examined using the Aminoantipyrine Phenol Cholesterol OxidasePeroxidase (CHOD-PAP) Method kit (Biolabo SAS, France) and preparation of sample were performed according to insert kit from the manufacturer. The serum triglyceride levels were measured using the Glycerol-3-phosphate oxidase-Peroxidase (GPO-PAP) method kit and the preparation of sample were performed according to insert kit from the manufacturer.

\section{Statistical analysis}

Demographic and clinical data were classified based on the presence of DN into two groups: The case group, type 2 diabetes patients who have DN ( $\mathrm{n}=35)$ and the control group, type 2 diabetes without DN (Non-DN) $(n=35)$, then analyzed using SPSS software version 24.0 for Windows.

Categorical scale data such as gender, body mass index (BMI) category, and the fasting blood glucose levels category were crosstabulated using the Chi-square test. While for numerical scale data such as age, weight, and height of the body, BMI, serum triglyceride level was analyzed using a two-independent sample T-test because their data were normally distributed. Data on fasting blood glucose levels, duration of diabetes, and serum total cholesterol levels were analyzed using the Mann Whitney $U$ test because of their abnormal distribution. These analyses were used to address potential sources of bias. 
The magnitude of relationship (odds ratio) between the serum total cholesterol levels, triglyceride levels and the presence of DN was analyzed by classifying them into normal and high, then crosstabulated using the Chi-square test to the determination of odd ratio.

\section{Ethical clearance}

This study was approved by the Local Research Ethics Committee of the Faculty of Medicine, Diponegoro University Semarang
Indonesia with the ethical clearance certificate number 365/EC/ KEPK/FK-UNDIP/VII/2019.

\section{Results}

Demographic and clinical data including the age, gender, weight, and height of the body, BMI fasting glucose levels, duration of diabetes, serum total cholesterol, and triglyceride level can be seen in table 1.

Table 1: Demographic characteristics of the participants $(\mathrm{N}=70)$.

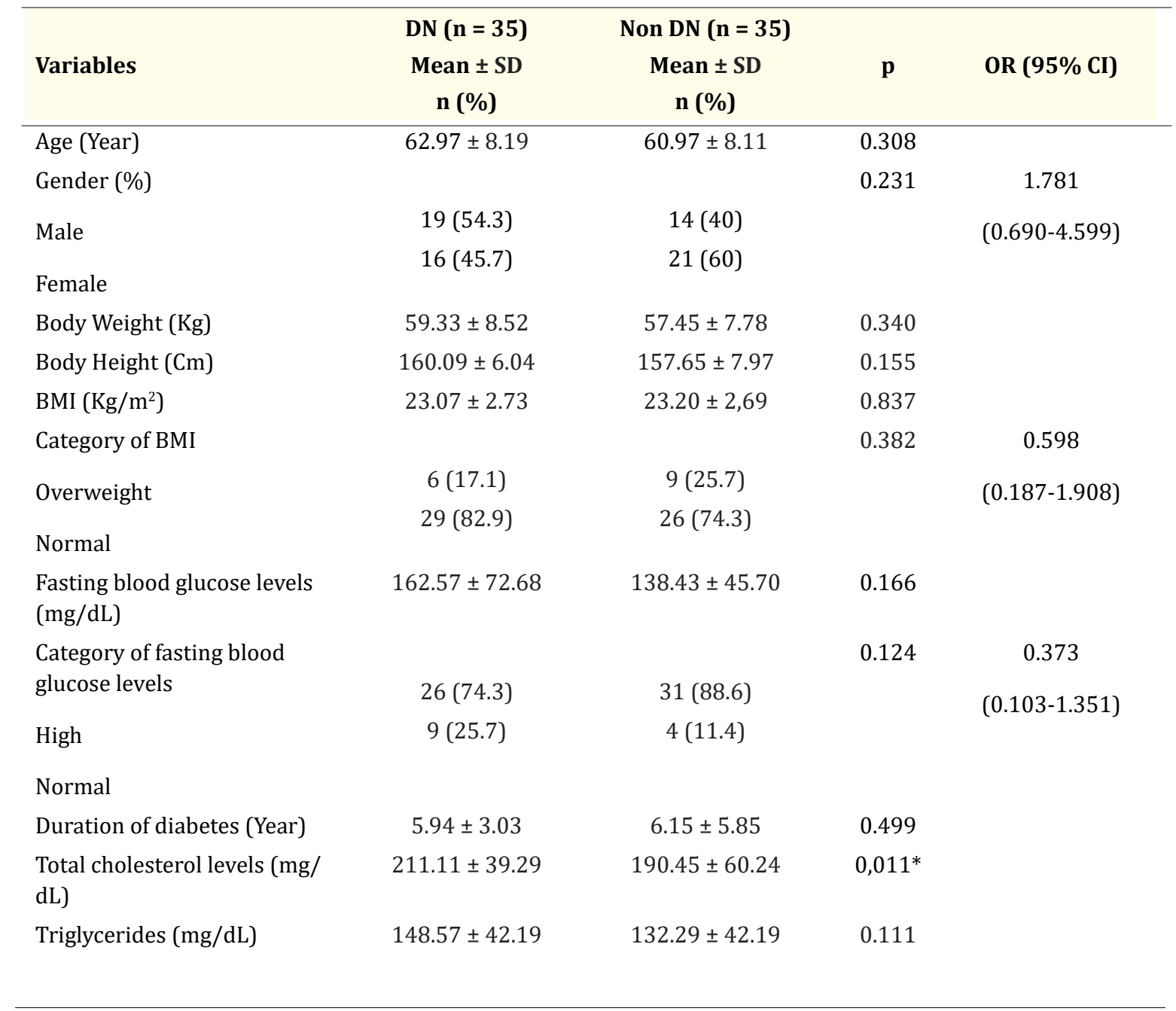

DN: Diabetes neuropathy, Non-DN: Non-diabetic neuropathy, Kg: Kilograms, Cm: Centimeters, Kg/m2: Kilograms/meter cubic, mg/dL: milligrams/desi litters, ${ }^{*}$ : p < 0.005, OR: Odds ratio, 95\%CI: 95\% Confidence intervals. 
The analysis of crosstabulation for the confounding variables regarding the demographic characteristics of subjects demonstrated that there was no significant association for most of the variables except the serum total cholesterol levels $(p=0.308$ for age, 0.231 for gender, 0.340 for body weight, 0.155 for body height, 0.837 for BMI, 0.166 for fasting blood glucose levels, 0.499 for the duration of diabetes, 0.111 for triglyceride levels and 0.011 for serum total cholesterol levels).

Data analysis was continued to determine the magnitude of association of the serum total cholesterol and triglyceride levels by categorized the variable of total cholesterol and triglyceride based on the WHO reference for them into two: high if the levels are more than $200 \mathrm{mg} / \mathrm{dL}$ for serum total cholesterol and more than $150 \mathrm{mg} /$ $\mathrm{dL}$ for triglyceride, and normal if the level is $200 \mathrm{mg} / \mathrm{dL}$ or less for total cholesterol and $150 \mathrm{mg} / \mathrm{dL}$ or less for triglycerides. The result of the analysis is in table 2 for the serum total cholesterol levels and table 3 for serum triglyceride levels.

Table 2: Association between serum total cholesterol levels and the presence of diabetic neuropathy.

\begin{tabular}{|c|c|c|c|c|}
\hline \multicolumn{5}{|c|}{ Group } \\
\hline & DN $(n=35)$ & $\begin{array}{l}\text { Non DN } \\
(n-35)\end{array}$ & $\mathbf{p}$ & OR 95\% CI \\
\hline \multicolumn{3}{|c|}{$\begin{array}{l}\text { Category of serum total Cholesterol } \\
\text { Levels }\end{array}$} & \multirow[t]{4}{*}{$0.017^{*}$} & \multirow{4}{*}{$\begin{array}{l}3.244 \\
(1.219-8.629)\end{array}$} \\
\hline High & $22(62.9)$ & $12(34.3)$ & & \\
\hline Normal & $13(37.1)$ & $23(65.7)$ & & \\
\hline Total & 35 (100) & $35(100)$ & & \\
\hline
\end{tabular}

DN: Diabetes neuropathy, Non-DN: Non-diabetic neuropathy, *: < 0.005, OR: Odds ratio, 95\%CI: 95\% Confidence intervals

Table 3: Association between serum triglyceride levels and the presence of diabetic neuropathy.

\begin{tabular}{lllll}
\hline & \multicolumn{1}{c}{ Group } & & \multicolumn{2}{l}{ OR } \\
DN (n= 35) & $\begin{array}{l}\text { Non DN } \\
(\mathbf{n}-35)\end{array}$ & $\mathbf{p}$ & $\mathbf{9 5 \%} \mathbf{C I}$ \\
\hline Category of Serum Triglyceride Levels & 0.051 & 2.647 \\
High & $18(51.4)$ & $10(28.6)$ & & $(0.985-7.113)$ \\
Normal & $17(48.6)$ & $25(71.4)$ & & \\
Total & $35(100)$ & $35(100)$ & & \\
\hline
\end{tabular}

DN: Diabetes neuropathy, Non-DN: Non-diabetic neuropathy, ${ }^{*}$ : $<$ 0.005, OR: Odds ratio, 95\%CI: 95\% Confidence intervals
Table 2 showed that the serum total cholesterol was associated significantly with the presence of the DN with an odds ratio of 3.244 ( $p=0.017$ and 95\% CI 1.219-8.629). This means that the people that have a high level of serum total cholesterol have a chance to have DN 3.244 times compared with the diabetes patient that has a normal level of serum total cholesterol. In contrast, table 3 showed that there is no significant association between the serum triglyceride level with the presence of the DN ( $p=0.051,95 \%$ CI 0.985-7.113).

\section{Discussion}

The DN is one of the microvascular complications of diabetes mellitus correlated with the chronic hyperglycemia condition resulting in the peripheral nerve dysfunction. There are several risk factors influencing the development of DN. Our analysis of the association of the confounding variables including the age, gender, weight and height of the body, BMI fasting glucose levels, duration of diabetes with the presence of DN in this study indicate that there is no significant association for the age, gender, weight and height of the body, BMI fasting glucose levels, duration of diabetes with the presence of DN.

These results are similar to the study of Popescu., et al. in 2016 that demonstrated that age influences the presence of DN but no for the glycemic index presented with $\mathrm{HbA1C}$ levels, duration of diabetes, and the BMI [12]. Another study conducted among Chinese people showed similar results. It is showed that age is an independent risk factor for the development of $\mathrm{DN}$, but no for other variables such as gender, duration of diabetes, BMI, and HbA1C levels [13]. These result of this study is different from the meta-analysis conducted by Liu., et al. in 2019 that presented that the duration of diabetes, ages, HbA1C levels are associated with significantly increased risks of DN [14].

The association of the serum total cholesterol levels with the presence of DN is still in debate. Our result demonstrated that serum total cholesterol levels are associated with the presence of DN among diabetic patients but no for serum triglyceride levels. Diabetic patients who have high serum total cholesterol levels increase the risk of 3.44 times to develop DN than diabetic patients without DN. This is different from the most studies which found that there was no significant correlation between serum total cholesterol levels with the presence of DN [10]. Liu., et al. 2019 showed that there is no significant difference in the serum total cholesterol level between DN and non-DN groups [14]. In contrast, previous 
studies found that there was a significant correlation between total cholesterol levels with the incidence of diabetic neuropathy [9]. Jende., et al. 2019 also presented that the serum total cholesterol level is associated with the peripheral nerve damage [15].

The role of high levels of serum total cholesterol in the DN is not fully understood. The previous study suggested that its effect is through oxidative stress mechanisms. Total cholesterol oxidizes reactive oxygen such as superoxide. Superoxide is a free radical that is very reactive and can cause tissue damage. Superoxide also plays a role in the activation of protein kinase $C$ by stimulating the synthesis of diacylglycerol (DAG). Increased DAG formation in the CCP pathway causes oxidative stress. Oxidative stress causes free radicals to attack and damage proteins, lipids, and nucleic acids. Oxidation of free radical products decreases biological activity, causing loss of metabolic energy, cell signaling, transport, and other major functions. Accumulation of damage can cause cell death through necrotic or apoptosis. Oxidative stress in neurons which results in axonopathy, and decreased regeneration capacity of axons that can cause negative symptoms in peripheral diabetic neuropathy. Oxidative stress on glial cells will cause the demyelination process so that a decrease in the speed of nerve delivery is obtained with manifestations in the form of painful symptoms. Oxidative stress on motor neurons activates caspase-3-dependent death mechanism so that it can cause cell death that manifests as abnormalities in motor neurons [16]. in this study, we did not have any data related the mechanisms of effect the serum total cholesterol in the pathogenesis of DN, so we could not explain its role on the DN development.

\section{Conclusions}

We conclude that there was a significant association between the serum total cholesterol levels and the presence of DN, but no for the serum triglycerides levels. Type 2 diabetes patients who have high serum total cholesterol levels the risk to suffer from DN is 3.44 times compared with type 2 diabetes patients who have normal serum total cholesterol levels. Further study is needed to determine the mechanisms of total cholesterol that affect the development of DN.

\section{Acknowledgments}

We thank Dr. Putri Rachmawati Dewi from Department of Pulmology and Cardiovascular, Wongsonegoro Hospital Semarang Indonesia for editing a draft of this manuscript.

\section{Author Contribution}

All authors have similar contribution for this work.

\section{Conflict of Interest}

There is no conflict of interest.

\section{Bibliography}

1. Juster-Switlyk K and Smith AG. "Updates in diabetic peripheral neuropathy”. F1000 Research 5 (2016): 738.

2. Pop-Busui R., et al. "Diabetic neuropathy: A position statement by the American diabetes association". Diabetes Care 40.1 (2017): 136-154.

3. Fowler MJ. "Microvascular and Macrovascular Complications of Diabetes". Clinical Diabetes 26.2 (2008): 77-82.

4. Yuniarti E., et al. "Analsis Biaya Terapi Penyakit Diabetes Melitus Pasien Jaminan Kesehatan Nasional di RS PKU Muhammadiyah Yogyakarta - Perbandingan Terhadap Tarif INA CBGs". Kebijakan Kesehatan Indonesia JKKI 4.3 (2015): 97-103.

5. Schreiber AK., et al. "Diabetic neuropathic pain: Physiopathology and treatment”. World Journal of Diabetes 6.3 (2015): 432444.

6. Suyanto Susanto A. "Faktor-faktor yang berhubungan dengan kejadian neuropati perifer diabetik". Jurnal Keperawatan dan Pemikiran Ilmiah 2.6 (2016): 1-7.

7. Al-Ani F., et al. "Dyslipidemia as a contributory factor in etiopathogenesis of diabetic neuropathy". Indian Journal of Endocrinology and Metabolism 15.2 (2011): 110-114.

8. Subbalakshmi NK., et al. "Influence of dyslipidemia on somatic neuropathy in type 2 diabetes mellitus". Nitte University Journal of Health Science 3.3 (2013): 25-30.

9. Aguiar PCM., et al. "The association of dyslipidemia and peripheral diabetic neuropathy: The influence of urea". Diabetology and Metabolic Syndrome 7 (2015): A30.

10. Booya F., et al. "Potential risk factors for diabetic neuropathy: A case control study". BMC Neurology 5 (2005): 24.

11. von Elm E., et al. "The Strengthening the Reporting of Observational Studies in Epidemiology (STROBE) statement: guidelines for reporting observational studies". Journal of Clinical Epidemiology 61.4 (200): 344-349. 
12. Popescue S., et al. "Ages as an independent factor for the development of neuropathy in diabetic patients". Clinical Interventional in Aging 11 (2016): 313-318.

13. Mao F., et al. "Ages as an independent risk factor for diabetic peripheral neuropathy in Chinese patients with type 2 diabetes". Aging and Disease 10.3 (2019): 592-600.

14. Liu X., et al. "The risk factors for diabetic peripheral neuropathy: A meta-analysis". PLoS ONE 14.2 (2019): e0212574.

15. Jende JME., et al. "Association of serum cholesterol levels with peripheral nerve damage in patients with type 2 diabetes". JAMA Netw Open 2.5 (2019): e194798.

16. Vincent AM., et al. "Hyperlipidemia: A new therapeutic target for diabetic neuropathy". Journal of the Peripheral Nervous System 14.4 (2009): 257-267.

\section{Assets from publication with us}

- Prompt Acknowledgement after receiving the article

- Thorough Double blinded peer review

- Rapid Publication

- Issue of Publication Certificate

- High visibility of your Published work

Website: www.actascientific.com/

Submit Article: www.actascientific.com/submission.php

Email us: editor@actascientific.com

Contact us: +919182824667 